\title{
Factors influencing satisfaction with oral contraceptive pills and injectables among past users in Kenya
}

\author{
George Odwe $^{1 \star}$, Joyce Mumah ${ }^{2}$, Francis Obare ${ }^{1}$, Marylene Wamukoya ${ }^{2}$, Kazuyo Machiyama ${ }^{3}$, \\ John Cleland ${ }^{3}$ and John Casterline ${ }^{4}$ \\ ${ }^{1}$ Population Council, Nairobi, Kenya, ${ }^{2}$ African Population and Health Research Center, Nairobi, Kenya, ${ }^{3}$ Faculty of \\ Epidemiology and Population Health, London School of Hygiene and Tropical Medicine, London, UK and ${ }^{4}$ Department \\ of Sociology, Ohio State University, Ohio, USA \\ ${ }^{\star}$ Corresponding author. Email: godwe@popcouncil.org
}

(Received 22 March 2018; revised 19 July 2018; accepted 21 August 2018; First published online 12 October 2018)

\begin{abstract}
This study examines factors associated with satisfaction with oral pills and injectables among past users in Kenya based on a baseline survey for the 2-year prospective longitudinal study Improving Measurement of Unintended Pregnancy and Unmet Need for Family Planning conducted in 2016. Married women aged 15-39 years were interviewed using a structured questionnaire that captured information on reproduction, contraceptive knowledge and beliefs and attitudes towards contraception in general and towards specific methods. A multivariate logistic regression analysis was used to examine factors that influenced satisfaction with oral pills and injectables among past users in one urban site (Nairobi slums) and one predominantly rural site (Homa Bay in western Kenya). Results showed that dissatisfaction with pills and injectables is common among past users in both rural and urban Kenya (ranging from 39\% to $56 \%$ ). The distinctive contribution of the study lies in its ability to relate method-specific beliefs to overall satisfaction. Perception of effectiveness, ease of use and safety for long-term use had statistically significant influences on satisfaction with pills in both urban and rural sites while partner's approval was only important in Nairobi. For injectables, the perception of safety for long-term use was significant in the urban but not the rural site. Unlike pills, the belief that members of a woman's social network had used a method and found it satisfactory was a particularly powerful influence on satisfaction ( $\mathrm{AOR}=2.8$ in rural and 3.2 in urban). Perception of accessibility and fears about infertility were not found to be statistically associated with satisfaction for either pills or injectables. Surprisingly, the effects of all perceived contraceptive attributes were the same for major socio-demographic strata of the populations. The findings underscore the need for targeted counselling and community-based communication interventions to address negative and erroneous perceptions about family planning methods.
\end{abstract}

Keywords: Satisfaction; Contraceptives; Past users

\section{Introduction}

Globally, there has been remarkable progress in the use of family planning. Contraceptive prevalence - defined as the proportion of currently married women using any method of contraception - increased from 55\% to 63\% between 1990 and 2010 (Alkema et al., 2013). Recent Demographic and Health Surveys (DHS) also show notable increases in contraceptive use in a number sub-Saharan Africa countries (Sharan et al., 2011). Despite this increase, unintended pregnancy - pregnancies that are mistimed or unwanted at the time of conception - remains a major concern in many settings (Sedgh et al., 2014). Studies reveal that high rate of contraceptive discontinuation is a major contributor to unintended pregnancies (Davidson et al., 1997; Fallon 
et al., 2008; Curtis et al., 2011). Dissatisfaction with the method and desire to get pregnant have been cited as main reasons for contraceptive discontinuation and non-use (Ali \& Cleland, 1995; Ali et al., 2012). Analysis based on DHS also reveals a number of reasons why many women in low-income countries are not using contraception despite wanting to avoid a pregnancy (Sedgh et al., 2016). Women commonly cite dissatisfaction due to concerns about side-effects and health risks, such as menstrual disruption and infertility, and social network disapproval as some of the major reasons for contraceptive non-use.

There has been a growing interest in method-specific satisfaction for its potential to improve quality of family planning services (Rosenberg et al., 1998). Direct measurement of overall satisfaction with a method is routinely used in clinical trials, acceptability studies and assessments of new service delivery approaches (Mitchel \& Thistle, 2004; Hubacher et al., 2015). However, it is rarely used in population-based studies. Instead, satisfaction with contraception is inferred from information routinely collected in DHS calendars on cause-specific discontinuation. Stopping a method because of side-effects, health concerns or a desire for a more effective method are typically grouped together as method-related reasons and interpreted as dissatisfaction (Ali \& Cleland, 2010; Ali et al., 2012). While this interpretation seems logical, it relies totally on the validity of a single self-reported reason, which may not capture a blend of different motivations, nor does it tell us anything about the satisfaction of women who stop for other reasons such as desire for a pregnancy nor, indeed, of continuing users. Direct measurement of satisfaction thus complements data on discontinuation in understanding contraceptive choices and diffusion of views about methods in social networks, as found in a study conducted in rural Kenya (Rutenberg \& Watkins, 1997). Satisfied current and past users are likely to be the main drivers of method adoption by never users (Fisher \& de Silva, 1986).

Satisfaction may be asked of current and of past users of a method. Generally, most studies find that majorities of current users of a method claim to be satisfied (Rosenfeld et al., 1993; Oddens, 1999). A study by Oddens found that satisfaction was very high among current users of oral pills (83\%), IUD (89\%) and condoms (53\%) (Oddens, 1999). This is unsurprising in view of the universal tendency to align attitudes to behaviour. Despite data showing that majorities of women prefer hormonal methods for their effectiveness and convenience, a large number of current users discontinue using them due to method-related factors. For example, according to the 2014 Kenya DHS report, the rates of all-cause 12-month discontinuation of pills and injectables in Kenya were $45 \%$ and $31 \%$, respectively (KNBS et al., 2015). The same report showed that about half of discontinuers did so for method-related reasons. Thus the very high levels of satisfaction among current users reported in most studies may be misleading. Accordingly, this paper relies on the reported satisfaction of past users. However, the current beliefs and opinions about specific methods among past users are based on women's own past experiences with the method. As a result, the findings may be affected by recall bias associated with information obtained retrospectively (Kopec \& Esdaile, 1990).

In a country such as Kenya where use of reversible methods has been reasonably high for many years and where discontinuation is also common, past users tend to outnumber current users. Past users also constitute a high proportion of women with unmet need for family planning in sub-Saharan Africa (Jain et al., 2013; Machiyama \& Cleland, 2013). Research shows that satisfaction influences method choice, including the resumption of use of a method, switching, compliance and continuation (Peipert et al., 2011). However, evidence on factors associated with method-specific satisfaction among past users is limited. The evidence is particularly scarce for low-income countries where low contraceptive use, a high discontinuation rate and a low switching rate to alternative methods are major concerns.

This study examines factors associated with satisfaction with hormonal contraceptive methods among past users in Kenya. The focus is specifically on determinants of satisfaction with oral pills and injectables among married women aged 15-39 who have used them in the past but are no longer using them at the time of the survey. The study used data obtained from two different 
settings in Kenya - Nairobi (urban site) and Homa Bay county (rural site). Oral pills and injectables were selected for the study because they were two of the three most popular contraceptives in both sites (Machiyama et al., 2018). Past users of the two methods also outnumbered current users in the two study settings. In the urban site, past and current users of injectables comprised $43 \%$ and $31 \%$ of the total sample, respectively, while the corresponding estimates for pills were $31 \%$ and $8 \%$. Similar relative magnitudes were observed in the rural site. Understanding the determinants of satisfaction with oral pills and injectables among past users is important for informing family planning programmes.

\section{Methods}

The analysis draws on a baseline survey for a 2-year prospective study entitled Improving Measurement of Unintended Pregnancy and Unmet Need for Family Planning, which aimed to advance knowledge of unmet need and unintended pregnancy, including contraceptive uptake and continuation. Detailed information on the background, rationale and study methodology is published elsewhere (Machiyama et al., 2017). The study was conducted between August and December 2016. Only married or co-habiting women aged between 15 and 39 years were eligible for inclusion. The upper age limit and enrolment of women in stable union was informed by the need to recruit women who were at potentially high risk of pregnancy during the observation period. The target sample size in each site was 2600 married women aged 15-39 years. The sample size was informed by the need to detect a $30 \%$ difference in reproductive outcomes (pregnancy, use and non-use of contraceptives) at 95\% confidence level and $80 \%$ power with an assumption of $10 \%$ non-response rate (Fleiss et al., 2013).

The study populations for the two sites were drawn using a different strategy. In the urban site, data collection was nested within the Nairobi Urban Health and Demographic Surveillance System - an on-going health and demographic surveillance site run by the African Population and Health Research Center. Data were obtained from two slum communities, Korogocho and Viwandani. A total of 5905 married or cohabiting women aged between 15 and 39 years were eligible for inclusion in the study. Out of these, 3093 women were randomly sampled. Interviews were completed with 2812 of the eligible women (1293 in Korogocho and 1519 in Viwandani) representing a $91 \%$ response rate. The final urban sample for analysis included 869 and 1218 past users of oral contraceptive pills and injectables, respectively.

In the rural site, participants were identified in two stages. The first stage involved a random sample of twelve sub-locations (the smallest administrative unit in Kenya) in each of three purposely identified sub-counties in Homa Bay County - namely Ndhiwa, Rachuonyo North and Rachuonyo South. All households in the selected sub-locations with currently married women aged 15-49 years were identified with the help of the local administration (village elders, subchiefs and chiefs). All individuals in those households were then listed to generate the sampling frame. In the second stage, a total of 3118 women aged 15-39 years were randomly sampled from among 5424 that were within that age range and were married at the time of listing. A total of 2424 women among sampled women completed the interviews, representing a $78 \%$ response rate. The final analytical sample comprised 576 and 1066 past users of oral contraceptive pills and injectables, respectively.

Face-to-face interviews of eligible women lasting an average of 45-60 minutes were conducted using a structured questionnaire. The questionnaire captured information on socio-demographic characteristics: contraceptive knowledge and use; reproduction; sexual activity; retrospective and prospective measures of fertility preferences; perceived partner's fertility preferences; perceived risk of pregnancy; and generic attitudes towards pregnancy prevention. In addition, the study was innovative by including questions on method-specific beliefs and attitudes. A total of ten opinions and beliefs were ascertained for all women aware of each of six modern methods (pills, injectables, implants, IUD, condoms, female sterilization) and two traditional methods (rhythm 
and withdrawal). Specifically, respondents were asked whether, in their opinion, a particular method was easy to access, easy to use and effective at preventing pregnancy. Participants were also asked whether, in their opinion, use of a particular method was likely to cause health problems, unpleasant side-effects, interference with menstruation or infertility, and whether it was safe to use for a long period without taking a break. In addition, respondents were asked to indicate their opinion on husband's/partner's approval of the method, use of the method by members of social networks of friends, neighbours and relatives, and whether their network members were satisfied with the method if they had ever used it. The dependent variable 'satisfaction with a method' was measured directly by asking ever users the following question: 'All things considered, were/are you satisfied or unsatisfied with using [METHOD]?' Respondents were required to indicate whether they were satisfied, dissatisfied or had mixed feelings/ neither satisfied nor dissatisfied. A binary variable was then created to capture satisfaction with a method, or otherwise.

Analysis controlled for socio-demographic factors: respondent's age (continuous); level of education (coded as $1=$ no education/primary incomplete, $2=$ completed primary and $3=$ secondary and above); number of living children (continuous); fertility preference (coded as $1=$ wants a child soon/within 2 years/undecided, $2=$ wants a child but would like to wait for 2 or more years, $3=$ doesn't want a/another child and $4=$ other (includes sterilized/cannot get pregnant $/ \mathrm{missing}$ ); and timing of last use (coded as $1=$ within last 3 years and $2=$ more than 3 years ago/do not know).

The analysis involved descriptive statistics, $\chi^{2}$ tests and estimation of a multivariate logistic regression model examining variations in the likelihood of being satisfied with oral pills and injectable contraceptives among past users. For multivariate analysis, each attribute was coded in a binary manner such that the most positive response was categorized as 1 , and 0 otherwise. For the rural sample, analysis took into account the sampling design by adjusting for clustering of individuals residing in the same village. Multivariate results are presented as adjusted odds ratios (AOR) with 95\% confidence intervals (CI). Correlation and the Variance Inflation Factor (VIF) analyses were performed to check for multicollinearity and tolerance values of all attributes. There were no major multicollinearity problems associated with most attributes for oral pills and injectable contraceptives among past users (mean VIF range 1.13-1.18).

\section{Results}

\section{Background characteristics}

Table 1 presents a summary of the sample characteristics. In Homa Bay, the majority of past pill and injectable users were aged 30-34 years, had an average of 3-4 children and had no formal or incomplete primary schooling. In Nairobi, the majority of past pill and injectable users were aged 30-34 years, had 1-2 children and had completed primary school. About a third (between 30\% and $41 \%$ ) of past pill and injectable users in both sites did not want a/another child. The majority of past pill users had last used the method more than 3 years ago (52\% in rural and $62 \%$ in urban) while the majority of past injectable users stopped using the method within the last 3 years (65\% in rural and $54 \%$ in urban). Approximately $22 \%$ and $32 \%$ of past pill and injectable users, respectively, were not currently using any method. The results on current contraceptive use showed a tendency to switch to a more effective method among past users of pills and injectables in both sites - the majority of past pill users were using injectables (31\% in Homa Bay and 36\% in Nairobi) while the majority of past injectable users were using implants (29\% in both sites). Implant use was also common among past pill users (21\% in both sites).

\section{Levels of satisfaction/dissatisfaction}

Table 2 presents the level of, and main reasons for, dissatisfaction with oral contraceptive pills and injectables among past users by site. The proportion of past users of pills who were 
Table 1. Distribution (\%) of characteristics of past users of pills and injectables, by rural/urban site

\begin{tabular}{|c|c|c|c|c|}
\hline \multirow[b]{2}{*}{ Characteristic } & \multicolumn{2}{|c|}{ Rural (Homa Bay) } & \multicolumn{2}{|c|}{ Urban (Nairobi) } \\
\hline & $\begin{array}{c}\text { Pills } \\
(N=576)\end{array}$ & $\begin{array}{c}\text { Injectables } \\
(N=1066)\end{array}$ & $\begin{array}{c}\text { Pills } \\
(N=869)\end{array}$ & $\begin{array}{c}\text { Injectables } \\
(N=1218)\end{array}$ \\
\hline \multicolumn{5}{|l|}{ Current age } \\
\hline $15-19$ & 3.0 & 3.8 & 0.5 & 0.7 \\
\hline $20-24$ & 19.4 & 25.7 & 11.9 & 16.0 \\
\hline $25-29$ & 25.9 & 25.3 & 29.3 & 28.4 \\
\hline $30-34$ & 31.8 & 29.4 & 33.5 & 33.7 \\
\hline $35-39$ & 20.0 & 15.9 & 24.9 & 21.3 \\
\hline \multicolumn{5}{|l|}{ Number of living children } \\
\hline None & 2.1 & 1.4 & 0.9 & 0.9 \\
\hline $1-2$ & 24.8 & 29.6 & 51.5 & 55.2 \\
\hline $3-4$ & 44.1 & 42.1 & 38.8 & 35.8 \\
\hline $5+$ & 29.0 & 26.9 & 8.8 & 8.1 \\
\hline \multicolumn{5}{|l|}{ Highest level of education } \\
\hline None/some primary & 39.2 & 44.3 & 23.3 & 24.9 \\
\hline Complete primary & 36.6 & 32.0 & 39.2 & 38.8 \\
\hline Secondary + & 24.1 & 23.7 & 37.5 & 36.4 \\
\hline \multicolumn{5}{|l|}{ Fertility preference } \\
\hline Wants a child soon/within 2 years or undecided & 13.4 & 16.9 & 20.7 & 23.4 \\
\hline Wants a child: wait 2 or more years & 40.1 & 41.1 & 40.7 & 41.2 \\
\hline Doesn't want a/another child & 41.8 & 37.7 & 30.1 & 33.6 \\
\hline Other $^{a}$ & 4.7 & 4.3 & 1.5 & 1.8 \\
\hline \multicolumn{5}{|l|}{ Timing of last use } \\
\hline Within last 3 years & 41.0 & 62.0 & 37.9 & 54.1 \\
\hline More than 3 years ago & 52.1 & 37.8 & 61.5 & 45.3 \\
\hline Don't know & 6.9 & 0.2 & 0.7 & 0.6 \\
\hline \multicolumn{5}{|l|}{ Current contraceptive use } \\
\hline Currently pregnant & 9.9 & 13.3 & 7.2 & 11.2 \\
\hline Not using & 21.7 & 32.4 & 22.7 & 32.0 \\
\hline Permanent methods & 4.0 & 3.8 & 1.2 & 1.0 \\
\hline IUD & 0.5 & 0.9 & 3.3 & 3.4 \\
\hline Implants & 20.8 & 28.8 & 21.2 & 29.1 \\
\hline Injectables & 30.6 & na & 35.8 & na \\
\hline
\end{tabular}


Table 1. Continued

\begin{tabular}{|c|c|c|c|c|}
\hline \multirow[b]{2}{*}{ Characteristic } & \multicolumn{2}{|c|}{ Rural (Homa Bay) } & \multicolumn{2}{|c|}{ Urban (Nairobi) } \\
\hline & $\begin{array}{c}\text { Pills } \\
(N=576)\end{array}$ & $\begin{array}{l}\text { Injectables } \\
(N=1066)\end{array}$ & $\begin{array}{c}\text { Pills } \\
(N=869)\end{array}$ & $\begin{array}{c}\text { Injectables } \\
(N=1218)\end{array}$ \\
\hline Pills & na & 3.8 & na & 12.8 \\
\hline Condoms & 7.8 & 9.8 & 1.3 & 1.9 \\
\hline LAM & 1.4 & 2.0 & 1.0 & 1.1 \\
\hline Traditional methods & 3.3 & 5.3 & 6.0 & 7.4 \\
\hline Emergency contraception & 0.0 & 0.0 & 0.3 & 0.2 \\
\hline Number of women $(N)$ & 576 & 1066 & 869 & 1218 \\
\hline
\end{tabular}

a Other includes women who were sterilized, those who indicated they cannot get pregnant and those who did not indicate their fertility preference.

LAM, Lactational amenorrhoea method; IUD, intra-uterine device; na, not applicable.

dissatisfied with the method was significantly higher among women in the urban than the rural site (56\% vs $44 \%)$. A similar difference was apparent for past injectable users (53\% vs 39\%). The results in Table 2 further show specific reasons for method dissatisfaction. In both sites, the majority of women were dissatisfied with injectables because of side-effects. Experience of irregular menstrual cycles was the second most cited reason for dissatisfaction with injectables, followed by concerns about health problems. These reasons were also common among dissatisfied past pill users across the two sites. In addition, appreciable proportions of women were dissatisfied with pills because they considered it was not an easy-to-use method ( $21 \%$ in rural site and $32 \%$ in urban site) or because they became pregnant while using it (19\% in the rural and $11 \%$ in the urban). The results further show that few women $(<10 \%)$ cited opposition of partners or others, lack of access, expense or stock-outs as a reason for dissatisfaction with pills or injectables.

\section{Opinions and attitudes towards oral pills}

Analysis of opinions about pills showed profound differences between satisfied and dissatisfied past users in both the rural and urban sites (Table 3). In general, satisfied past users of pills were significantly more likely than those dissatisfied to report positive attributes about pills and less likely to report negative beliefs. The contrasts between satisfied and dissatisfied users were particularly pronounced for beliefs about ease of use, effectiveness and likelihood of causing serious health problems, side-effects and menstrual disruption. Conversely, satisfaction was unrelated to ease of access and only small minorities of either satisfied or dissatisfied users expressed concerns about permanent damage to future childbearing. The single largest difference between rural and urban respondents related to beliefs about serious health problems; such concerns were much more common in the rural than in the urban site, among both satisfied and dissatisfied users.

\section{Opinions and attitudes towards injectables}

Table 4 presents opinions and attitudes towards injectables among satisfied and dissatisfied past users by site. As in the case of pill users, satisfied injectable users judged the method more positively on every attribute than did dissatisfied users. Differences were relatively small for ease of access, ease of use, effectiveness, perceived prevalence of use in social networks and concerns about fertility impairment. Conversely, they were particularly large for perceived likelihood of serious health problems, menstrual interference and unpleasant side-effects. Compared with past pill users, injectable users, both satisfied and dissatisfied, were more likely to rate their method as 
Table 2. Level of, and main reasons for, dissatisfaction with pills and injectables among past users by rural/urban site

\begin{tabular}{|c|c|c|c|c|}
\hline & \multicolumn{2}{|c|}{ Pills } & \multicolumn{2}{|c|}{ Injectables } \\
\hline & $\begin{array}{c}\text { Rural } \\
(\%)\end{array}$ & $\begin{array}{l}\text { Urban } \\
(\%)\end{array}$ & $\begin{array}{c}\text { Rural } \\
(\%)\end{array}$ & $\begin{array}{c}\text { Urban } \\
(\%)\end{array}$ \\
\hline \multicolumn{5}{|c|}{$\begin{array}{l}\text { All things considered, are/were you satisfied or } \\
\text { unsatisfied with using [METHOD]? }\end{array}$} \\
\hline Satisfied & 38.4 & 41.3 & 44.9 & 44.9 \\
\hline Dissatisfied & 43.6 & 55.8 & 38.7 & 53.2 \\
\hline Mixed/neither & 6.3 & 2.3 & 9.0 & 1.3 \\
\hline Missing & 11.8 & 0.6 & 7.3 & 0.6 \\
\hline Number of women $(N)$ & 576 & 1066 & 869 & 1218 \\
\hline \multicolumn{5}{|l|}{ Main reasons for dissatisfaction ${ }^{a}$} \\
\hline Experienced side-effects & 47.4 & 51.1 & 66.3 & 56.2 \\
\hline Irregular menstrual cycle & 35.9 & 16.3 & 62.5 & 52.5 \\
\hline Concerned about health problems & 15.9 & 15.9 & 23.0 & 22.1 \\
\hline Got pregnant while using & 19.1 & 11.1 & 6.5 & 8.0 \\
\hline Not easy to use & 20.7 & 31.5 & 1.5 & 0.6 \\
\hline Respondent/husband/others opposed & 8.4 & 2.6 & 7.0 & 2.5 \\
\hline Lack of access/cost too much/stock-out & 3.6 & 0.4 & 6.3 & 0.2 \\
\hline Other & 2.8 & 2.6 & 7.0 & 5.4 \\
\hline Number of women $(N)$ & 251 & 485 & 413 & 648 \\
\hline
\end{tabular}

${ }^{a}$ Multiple responses were allowed.

easy to use and effective, but more likely to cause menstrual disturbance. In the urban but not the rural site, injectable users were more concerned about fertility impairment than pill users.

\section{Multivariate analysis}

Multivariate logistic regression was used to explore the relative contribution of the variation in each opinion and belief on the satisfaction score among past users when all the attributes were considered together. As shown in Table 5, satisfaction with oral contraceptive pills among respondents in the rural site was more likely for those reporting that the method was effective in preventing pregnancy ( $\mathrm{AOR} 3.16, \mathrm{CI}=1.96-5.08$ ), easy to use ( $\mathrm{AOR} 2.14, \mathrm{CI}=1.39-3.310$ ) and safe to use for a long time without stopping (AOR 1.97, CI =1.26-3.08). Furthermore, satisfaction with pills was 1.74 and 1.82 times more likely, respectively, among women who perceived that the pill does not cause side-effects or interfere with the menstrual cycle compared with those who felt otherwise. However, ease of access, belief that the method might cause serious health problems or permanent infertility and husband's approval were not significantly related to satisfaction. Similar results were obtained in the urban site. Two major differences between sites are apparent. In the urban but not the rural site, concerns about serious health problems and perceived husband's approval of the method were significant predictors of satisfaction.

Table 6 presents the results of the multivariate logistic regression model examining variations in the likelihood of satisfaction with injectables among past users by site. Perception of 
Table 3. Opinions and attitudes towards pills among satisfied and dissatisfied past pill users by rural/urban site

\begin{tabular}{|c|c|c|c|c|}
\hline & \multicolumn{2}{|c|}{ Rural } & \multicolumn{2}{|c|}{ Urban } \\
\hline & $\begin{array}{l}\text { Satisfied } \\
\quad(\%)\end{array}$ & $\begin{array}{l}\text { Dissatisfied } \\
(\%)\end{array}$ & $\begin{array}{l}\text { Satisfied } \\
\quad(\%)\end{array}$ & $\begin{array}{l}\text { Dissatisfied } \\
\quad(\%)\end{array}$ \\
\hline \multicolumn{5}{|l|}{ Positive attributes } \\
\hline Method easy to obtain & 86.4 & $80.9^{\text {ns }}$ & 95.8 & $92.8^{\mathrm{ns}}$ \\
\hline Method easy to use & 52.9 & $24.7^{\star \star \star}$ & 59.1 & $27.6^{\star \star \star}$ \\
\hline $\begin{array}{l}\text { Most or about a half of friends/relatives/neighbours have used } \\
\text { method }\end{array}$ & 21.7 & $15.5^{\mathrm{ns}}$ & 30.4 & $22.9^{\star *}$ \\
\hline Friends/relatives/neighbours used method and were satisfied ${ }^{a}$ & 62.2 & $26.2^{\star \star \star}$ & 78.3 & $37.9^{\star \star \star}$ \\
\hline Method is very effective in preventing pregnancy & 84.2 & $53.8^{\star \star \star}$ & 85.0 & $60.8^{\star \star \star}$ \\
\hline Husband/partner approves use of method & 63.4 & $49.4^{\star \star}$ & 83.0 & $63.9^{\star \star \star}$ \\
\hline \multicolumn{5}{|l|}{ Negative attributes } \\
\hline Method likely to cause serious health problems & 30.8 & $55.0^{\star \star \star}$ & 7.0 & $19.2^{\star \star \star}$ \\
\hline Method likely to interfere with regular menses & 47.5 & $70.9^{\star \star \star}$ & 27.9 & $50.5^{\star \star \star}$ \\
\hline Method likely to cause unpleasant side-effects & 48.4 & $78.9^{\star \star \star}$ & 37.9 & $61.7^{\star \star \star}$ \\
\hline May not have children after stopping use & 14.0 & $17.1^{\mathrm{ns}}$ & 7.5 & $17.5^{\star \star \star}$ \\
\hline Not safe to use method for long without stopping & 59.7 & $80.1^{\star \star \star}$ & 55.7 & $78.8^{\star \star \star}$ \\
\hline Number of women $(N)$ & 221 & 251 & 259 & 485 \\
\hline
\end{tabular}

Respondents who indicated 'mixed/neither' to the question on satisfaction were excluded.

${ }^{a}$ Only includes respondents whose friends/relatives/neighbours had used the method.

${ }^{\star \star \star} p<0.001 ;{ }^{* \star} p<0.01 ;{ }^{*} p<0.05$; ns not significant.

effectiveness in preventing pregnancy, ease of use, absence of unpleasant side-effects and satisfied use by social networks were the most powerful predictors of satisfaction with injectables in the rural site (OR range between 2.44 and 2.78). Furthermore, satisfaction with injectables was more likely among past users who perceived that it does not cause serious health problems $(\mathrm{OR}=1.55$, $\mathrm{CI}=1.11-2.18)$, interfere with menses $(\mathrm{OR}=1.86, \mathrm{CI}=1.15-3.01)$, cause infertility $(\mathrm{OR}=1.64$, $\mathrm{CI}=1.08-2.51)$ and that their husband/partner approves $(\mathrm{OR}=1.49, \mathrm{CI}=1.05-2.12)$. A similar pattern of result was apparent in the urban site, where absence of serious health concerns and the perception of widespread satisfactory use among friends, neighbours and relatives emerged as the most powerful predictors (ORs of 3.25 and 3.28, respectively). Unlike in the rural site, past injectable users who perceived that the method was safe to use for a long period of time were more likely to be satisfied ( $\mathrm{OR}=2.25, \mathrm{CI}=1.65-3.07)$ than those who felt otherwise.

\section{Discussion}

This study examined factors influencing satisfaction with oral contraceptive pills and injectables among past users in rural and urban settings in Kenya. It specifically focused on women's opinions and beliefs on contraceptive attributes that may be associated with satisfaction among past users of oral contraceptive pills and injectables. The decision to omit examination of satisfaction among current users was based on the fact that the very high levels of satisfaction (around 90\% for injectable users in both sites and pill users in Nairobi in the current study) are likely to be misleading. Moreover, past users outnumber current users and thus their evaluations of methods may be a key influence on the general climate of opinion on specific methods in 
Table 4. Opinions and attitudes towards injectables among satisfied and dissatisfied past users by rural/urban site

\begin{tabular}{|c|c|c|c|c|}
\hline & \multicolumn{2}{|c|}{ Rural } & \multicolumn{2}{|c|}{ Urban } \\
\hline & $\begin{array}{c}\text { Satisfied } \\
(\%)\end{array}$ & $\begin{array}{c}\text { Dissatisfied } \\
(\%)\end{array}$ & $\begin{array}{c}\text { Satisfied } \\
(\%)\end{array}$ & $\begin{array}{c}\text { Dissatisfied } \\
(\%)\end{array}$ \\
\hline \multicolumn{5}{|l|}{ Positive attributes } \\
\hline Method easy to obtain & 93.3 & $89.6 n s$ & 97.8 & $96.0^{\text {ns }}$ \\
\hline Method easy to use & 96.5 & $83.3^{\star \star \star}$ & 96.3 & $83.8^{\star \star \star}$ \\
\hline Most of friends/relatives/neighbours have used method & 71.6 & $62.7^{\star \star}$ & 68.9 & $59.0^{\star *}$ \\
\hline Friends/relatives/neighbours used method and were satisfied ${ }^{a}$ & 69.5 & $30.7^{\star \star \star}$ & 77.4 & $35.9^{\star \star \star}$ \\
\hline Method very effective in preventing pregnancy & 96.7 & $87.7^{\star \star \star}$ & 96.2 & $77.6^{\star \star \star}$ \\
\hline Husband/partner approves use of method & 79.5 & $68.5^{\star \star \star}$ & 88.1 & $69.0^{\star \star \star}$ \\
\hline \multicolumn{5}{|l|}{ Negative attributes } \\
\hline Method likely to cause serious health problems & 24.2 & $53.8^{\star \star \star}$ & 7.3 & $35.7^{\star \star \star}$ \\
\hline Method likely to interfere with regular menses & 76.4 & $93.0^{\star \star *}$ & 70.9 & $91.5^{\star \star \star}$ \\
\hline Method likely to cause unpleasant side-effects & 54.7 & $84.0^{\star \star \star}$ & 49.0 & $79.5^{\star \star \star}$ \\
\hline May not have children after stopping to use & 13.2 & $19.1^{\star}$ & 27.2 & $32.3^{\mathrm{ns}}$ \\
\hline Not safe to use method for long without stopping & 67.9 & $78.9^{\star \star \star}$ & 55.0 & $82.1^{\star \star \star}$ \\
\hline Number of women $(N)$ & 479 & 413 & 547 & 648 \\
\hline
\end{tabular}

Respondents who indicated 'mixed/neither' to the question on satisfaction were excluded.

${ }^{a}$ Only includes respondents whose friends/relatives/neighbours had used the method.

${ }^{\star \star \star} p<0.001 ;{ }^{* \star} p<0.01 ;{ }^{*} p<0.05$; ns not significant.

communities, thereby influencing method-specific adoption and perhaps continuation. Further analysis revealed statistically insignificant variation in socio-demographic characteristics (age, level of education and fertility preference) between current and past users of pills and injectables in both sites (results not shown). The findings contribute to the literature on predictors of method-specific satisfaction and contraceptive continuation.

The level of satisfaction among past users was remarkably similar across the two methods in both sites, ranging from $38 \%$ to $45 \%$. Comparable population-based data are unavailable for subSaharan Africa but these estimates are consistent with discontinuation rates for pills and injectables in the region. They are also broadly similar to estimates from Europe and USA. For example, a German study found a level of $58 \%$ satisfaction among past users of oral contraceptives (Oddens, 1999) while similar levels may be inferred from a study in the USA for oral contraception and injectable users (Peipert et al., 2011).

As expected, the results showed widespread differences in opinions about pills and injectables between satisfied and dissatisfied past users. For both methods, these differences were particularly pronounced for beliefs about the likelihood of serious health problems, unpleasant sideeffects and menstrual disruption. Again, the findings are consistent with abundant evidence on self-reported reasons for discontinuation (Trlin \& Perry, 1982). However, it is of interest that substantial proportions of satisfied past users, ranging from $38 \%$ to $55 \%$, associated the method with unpleasant side-effects and the majority believed that prolonged use without taking a break would be unsafe. In Homa Bay, but not in the Nairobi site, the belief among satisfied past users that the method is likely to cause serious health problems was common: $24 \%$ for injectables and $31 \%$ for pills. Clearly, overall satisfaction with a method can co-exist with negative beliefs, either 
Table 5. Multivariate logistic regression model examining variations in the likelihood of satisfaction with oral contraceptive pill among past users by rural/urban site

\begin{tabular}{|c|c|c|c|c|c|c|}
\hline & \multicolumn{3}{|c|}{ Rural } & \multicolumn{3}{|c|}{ Urban } \\
\hline & OR & {$[95 \% \mathrm{Cl}]$} & $p>z$ & OR & {$[95 \% \mathrm{Cl}]$} & $p>z$ \\
\hline \multicolumn{7}{|l|}{ Contraceptive attributes } \\
\hline Easy to find & 0.96 & {$[0.56-1.67]$} & 0.893 & 1.55 & {$[0.79-3.06]$} & 0.202 \\
\hline Effectively prevents pregnancy & 3.16 & {$[1.96-5.08]$} & $<0.001$ & 2.05 & {$[1.38-3.04]$} & $<0.001$ \\
\hline Easy to use & 2.14 & {$[1.39-3.31]$} & 0.001 & 2.44 & {$[1.74-3.43]$} & 0.001 \\
\hline Doesn't cause health problems & 1.23 & {$[0.78-1.92]$} & 0.375 & 1.75 & {$[1.03-2.97]$} & 0.038 \\
\hline Doesn't interfere with menses & 1.82 & {$[1.16-2.84]$} & 0.009 & 1.60 & {$[1.12-2.28]$} & 0.011 \\
\hline Doesn't cause side-effects & 1.74 & {$[1.08-2.79]$} & 0.023 & 1.55 & {$[1.08-2.21]$} & 0.016 \\
\hline Safe for long use & 1.97 & {$[1.26-3.08]$} & 0.003 & 1.76 & {$[1.25-2.49]$} & 0.001 \\
\hline Doesn't cause infertility & 0.87 & {$[0.49-1.53]$} & 0.628 & 1.52 & {$[0.89-2.62]$} & 0.126 \\
\hline Social network ${ }^{\mathrm{a}}$ tried \& satisfied & 1.74 & {$[0.91-3.31]$} & 0.093 & 1.57 & {$[1.05-2.33]$} & 0.026 \\
\hline Husband/partner approves & 1.07 & {$[0.71-1.62]$} & 0.750 & 2.23 & {$[1.53-3.24]$} & 0.001 \\
\hline \multicolumn{7}{|l|}{ Socio-demographic variables } \\
\hline Age & 1.00 & {$[0.95-1.05]$} & 0.890 & 1.01 & {$[0.98-1.05]$} & 0.475 \\
\hline \multicolumn{7}{|l|}{ Level of education } \\
\hline \multicolumn{7}{|l|}{ No school/some primary (Ref.) } \\
\hline Completed primary & 1.61 & {$[1.01-2.58]$} & 0.046 & 1.12 & {$[0.73-1.71]$} & 0.612 \\
\hline Secondary + & 1.17 & {$[0.69-1.98]$} & 0.564 & 1.17 & {$[0.75-1.83]$} & 0.477 \\
\hline Number of live births & 1.02 & {$[0.87-1.19]$} & 0.821 & 0.95 & {$[0.82-1.11]$} & 0.531 \\
\hline \multicolumn{7}{|l|}{ Fertility preference } \\
\hline \multicolumn{7}{|l|}{$\begin{array}{l}\text { Wants a child soon/within } 2 \text { years or } \\
\text { undecided (Ref.) }\end{array}$} \\
\hline Wants a child: wait 2 or more years & 0.94 & {$[0.49-1.81]$} & 0.855 & 0.98 & {$[0.64-1.50]$} & 0.919 \\
\hline Doesn't want a/another child & 0.82 & {$[0.41-1.66]$} & 0.582 & 0.65 & {$[0.41-1.03]$} & 0.067 \\
\hline Other ${ }^{\mathrm{b}}$ & 1.36 & {$[0.43-4.32]$} & 0.605 & 0.19 & {$[0.03-1.11]$} & 0.066 \\
\hline \multicolumn{7}{|l|}{ Timing of last use } \\
\hline \multicolumn{7}{|l|}{ Within last 3 years (Ref.) } \\
\hline More than 3 years ago/don't know & 1.01 & {$[0.66-1.57]$} & 0.948 & 0.85 & {$[0.61-1.19]$} & 0.349 \\
\hline
\end{tabular}

${ }^{\mathrm{a}}$ Social network includes friends, relatives and neighbours.

bother includes women who were sterilized, those who indicated they cannot get pregnant and those who did not indicate their fertility preference.

Ref.: Reference category; $\mathrm{Cl}$ : confidence interval.

based on experience, such as side-effects, or on unfounded fears, as in the case of serious health problems or the dangers of prolonged use.

These simple descriptive results provide a valuable insight into the contraceptive culture of Kenya. Contraceptive practice is well established in the slums of Nairobi and has increased 
Table 6. Multivariate logistic regression model examining variations in the likelihood of satisfaction with injectables among past users by rural/urban site

\begin{tabular}{|c|c|c|c|c|c|c|}
\hline & \multicolumn{3}{|c|}{ Rural site } & \multicolumn{3}{|c|}{ Urban site } \\
\hline & $\mathrm{OR}$ & {$[95 \% \mathrm{Cl}]$} & $p>z$ & OR & {$[95 \% \mathrm{Cl}]$} & $p>z$ \\
\hline \multicolumn{7}{|l|}{ Contraceptive attributes } \\
\hline Easy to find & 1.58 & {$[0.91-2.74]$} & 0.104 & 0.80 & {$[0.31-2.05]$} & 0.644 \\
\hline Effectively prevents pregnancy & 2.50 & {$[1.28-4.88]$} & 0.007 & 2.72 & {$[1.56-4.77]$} & $<0.001$ \\
\hline Easy to use & 2.66 & {$[1.44-4.92]$} & 0.002 & 2.63 & {$[1.40-4.94]$} & 0.003 \\
\hline Doesn't cause health problems & 1.55 & {$[1.11-2.18]$} & 0.011 & 3.25 & {$[2.15-4.93]$} & $<0.001$ \\
\hline Doesn't interfere with menses & 1.86 & {$[1.15-3.01]$} & 0.012 & 1.97 & {$[1.30-2.97]$} & 0.001 \\
\hline Doesn't cause side-effects & 2.44 & {$[1.69-3.54]$} & $<0.001$ & 2.78 & {$[2.01-3.83]$} & $<0.001$ \\
\hline Safe for long use & 1.42 & {$[1.00-2.01]$} & 0.050 & 2.25 & {$[1.65-3.07]$} & $<0.001$ \\
\hline Doesn't cause infertility & 1.64 & {$[1.08-2.51]$} & 0.021 & 0.94 & {$[0.69-1.30]$} & 0.727 \\
\hline Social network ${ }^{a}$ tried \& satisfied & 2.78 & {$[2.03-3.82]$} & 0.001 & 3.28 & {$[2.45-4.39]$} & $<0.001$ \\
\hline Husband/partner approves & 1.49 & {$[1.05-2.12]$} & 0.026 & 1.92 & {$[1.31-2.81]$} & 0.001 \\
\hline \multicolumn{7}{|l|}{ Socio-demographic variables } \\
\hline Age & 1.02 & {$[0.98-1.06]$} & 0.272 & 1.01 & {$[0.97-1.04]$} & 0.669 \\
\hline \multicolumn{7}{|l|}{ Level of education } \\
\hline \multicolumn{7}{|l|}{ No school/some primary (Ref.) } \\
\hline Completed primary & 0.90 & {$[0.63-1.28]$} & 0.568 & 0.82 & {$[0.56-1.19]$} & 0.302 \\
\hline Secondary + & 0.79 & {$[0.54-1.17]$} & 0.246 & 0.78 & {$[0.52-1.15]$} & 0.208 \\
\hline Number of live births & 0.88 & {$[0.78-0.99]$} & 0.041 & 0.89 & {$[0.78-1.02]$} & 0.093 \\
\hline \multicolumn{7}{|l|}{ Fertility preference } \\
\hline \multicolumn{7}{|c|}{ Wants a child soon/within 2 years/undecided (Ref.) } \\
\hline Wants a child: wait 2 or more years & 0.77 & {$[0.47-1.19]$} & 0.231 & 0.61 & {$[0.41-0.88]$} & 0.010 \\
\hline Doesn't want a/another child & 0.80 & {$[0.49-1.30]$} & 0.360 & 0.58 & {$[0.38-0.86]$} & 0.008 \\
\hline Other ${ }^{b}$ & 1.11 & {$[0.47-2.62]$} & 0.813 & 0.60 & {$[0.21-1.77]$} & 0.359 \\
\hline \multicolumn{7}{|l|}{ Timing of last use } \\
\hline \multicolumn{7}{|l|}{ Within last 3 years (Ref.) } \\
\hline More than 3 years ago/don't know & 0.81 & {$[0.59-1.12]$} & 0.212 & 0.78 & {$[0.58-1.05]$} & 1.000 \\
\hline
\end{tabular}

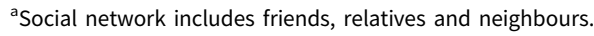

bOther includes women who were sterilized, those who indicated they cannot get pregnant and those who did not indicate their fertility preference.

Ref.: Reference category; $\mathrm{Cl}$ : confidence interval.

rapidly in Homa Bay. In both sites, injectables are the most commonly used method. Yet even this method is viewed with a degree of fear and suspicion. Clear majorities, both among satisfied and dissatisfied users, believe that prolonged use is unsafe and substantial minorities think that it is likely to cause serious health problems. While the growing imperative to regulate childbearing 
can stifle these concerns, the results suggest that commitment to the method may be shallow, with the consequence that discontinuation is high.

These results may also be relevant to an understanding of reproductive change in West Africa, where urban fertility has declined substantially with a concomitant rise in modern method use (Askew et al., 2017). In Accra, for instance, well-educated urban women are achieving small families with a blend of less effective, but perhaps less-threatening methods such as periodic abstinence, withdrawal and condoms with backup from emergency contraception, rather than from readily available highly effective methods, such as injectables (Marston et al., 2017). The concerns about hormonal methods among women in Accra and elsewhere in the cities of West Africa may well prove to be similar to those expressed by Nairobi women.

The multivariate results shed more light on the predictors of satisfaction with pills and injectables among past users. Attributes such as accessibility, and fears about infertility, generally had no influence on satisfaction with either method in either the rural or urban site. For both methods, perceived effectiveness and ease of use were strong predictors of satisfaction in both sites. However, past users, in general, were less likely to rate pills as effective and easy to use than injectables and this difference helps to explain the higher levels of use of injectables than pills in both sites. Previous studies show that dissatisfaction with the contraceptive pill is common due to accidental pregnancy attributed to non-compliance (Rosenberg et al., 1998; Hooper, 2010). For the pill, the predictive strengths of other beliefs, though statistically significant in some cases, were relatively weak compared with ease of use and perceived effectiveness, with the exception of views about the safety of long-term use and, in Nairobi, of husband's approval.

Interpretation of results is complex for injectables. Most beliefs about the attributes of this method had strong effects on satisfaction and no decisive influence could be identified. Furthermore, the effects were generally similar across the sites, though health concerns and perceived safety of long-term use appeared to be more important in the urban than the rural site.

One major difference between the results for pills and injectables was the effect on satisfaction of perceived social network experience, which was much stronger for injectables than for pills. The results for injectables are consistent with a large body of previous research showing that an individual's contraceptive behaviour is heavily influenced by the experiences and views of friends, neighbours and relatives (Behrman et al., 2002; Yee \& Simon, 2010). A large number of satisfied users may affect uptake of a method among never users and continuation of current users by transmitting positive information. The power of social influence goes a long way to explaining the narrow method-mix in many countries. Most women are not autonomous in their decisions to start a contraceptive method. On the contrary, their natural preference is for a familiar method that has been used successfully by friends, neighbours or relatives. This interpretation is consistent with qualitative evidence for Kenya (Rutenberg \& Watkins, 1997). While women respect the information given by family planning providers, their contraceptive choices are largely determined on the basis of conversations with friends. Why the social network effect was much weaker for pills is unclear but may simply reflect the fact that pill use was much less common than injectable use in both sites.

Socio-demographic factors - age, number of living children, level of education and duration since last time respondents used a method - had insignificant effects on satisfaction with oral contraceptive pills and injectables in both the rural and urban samples. In contrast, much of the literature on contraceptive use and method choice has documented large effects of demographic and social factors, such as age, parity and schooling. The implication of this surprising result is that the effects of these perceived contraceptive attributes are uniform across major strata of the population.

The study has some limitations. Satisfaction is a subjective judgment, hence some women may have indicated dissatisfied with a method due to a strong preference for another method, or because they are unlikely to use the concerned method in the future. Another limitation could be attributed to the 'halo effect', that is, the tendency to evaluate specific attributes of a person (in this case, a method) based on an overall judgment (Van Doorn, 2008). It is also possible that 
dissatisfaction with a method may be underestimated given a tendency to give positive responses during interviews. The analysis did not take into account current contraceptive use status among past users though there is a possibility that dissatisfaction among past users is conditional on current use status. The omission of current use status was deliberate since evaluating its effect was beyond the scope of the current study. Despite the aforementioned limitations, relying on past users provides a sizeable number of dissatisfied ever users of a method that is rarely found among current users.

In conclusion, prior evidence from population-based studies in Africa on method-specific satisfaction is rare and, to the authors' knowledge, no study in the region has measured in such detail beliefs about methods or attempted to investigate links between these beliefs and overall satisfaction. The findings are broadly consistent with the literature from industrialized countries on method satisfaction. Dissatisfaction with pills and injectables is common among past users in both rural and urban Kenya mainly due to health-related concerns. Worries about impairment of childbearing did not emerge as a major influence on satisfaction but doubts about the safety of prolonged use were more important. Some negative and erroneous perceptions can be addressed by targeted counselling or wider community-based communication efforts. Other negative perceptions, such as unpleasant side-effects and menstrual disruption, are based on individual experience and cannot easily be addressed by counselling, education or communication.

Acknowledgments. The authors are indebted to the women who participated in this study and the team members who worked at the two study sites, Nairobi and Homa-Bay, and at APHRC, and Population Council, Kenya. The authors would like to thank the members of the STEP UP Consortium Advisory Group and Senior Management Team for their invaluable feedback in the design and implementation of the study.

Ethical Approval. The authors assert that all procedures contributing to this work comply with the ethical standards of the relevant national and institutional committees on human experimentation and with the Helsinki Declaration of 1975, as revised in 2008. Ethical approval for the study was obtained from the Institutional Review Boards of the London School of Hygiene and Tropical Medicine and Population Council, as well as from the AMREF Ethics and Scientific Review Committee for the Nairobi site and Kenyatta National Hospital-University of Nairobi Ethics and Research Committee for the Homa-Bay site.

Conflicts of Interest. The authors have no conflicts of interest to declare.

Funding. The Improving Measurement of Unintended Pregnancy and Unmet Need for Family Planning study was funded by the Department for International Development (DfID) through the STEP UP (Strengthening Evidence for Programming on Unintended Pregnancy) Research Consortium.

\section{References}

Ali M and Cleland J (1995) Contraceptive discontinuation in six developing countries: a cause-specific analysis. International Family Planning Perspectives 21(3), 92-97.

Ali MM and Cleland J (2010) Oral contraceptive discontinuation and its aftermath in 19 developing countries. Contraception 81(1), 22-29.

Ali MM, Cleland JG and Shah IH and WHO (2012) Causes and Consequences of Contraceptive Discontinuation: Evidence from 60 Demographic and Health Surveys. World Health Organization, Geneva.

Alkema L, Kantorova V, Menozzi C and Biddlecom A (2013) National regional and global rates and trends in contraceptive prevalence and unmet need for family planning between 1990 and 2015: a systematic and comprehensive analysis. The Lancet 381(9878), 1642-1652.

Askew I, Maggwa N and Obare F (2017) Fertility transitions in Ghana and Kenya: trends determinants and implications for policy and programs. Population and Development Review 43, 289-307.

Behrman JR, Kohler H-P and Watkins SC (2002) Social networks and changes in contraceptive use over time: evidence from a longitudinal study in rural Kenya. Demography 39(4), 713-738.

Curtis S, Xe Evens E and Sambisa W (2011) Contraceptive discontinuation and unintended pregnancy: an imperfect relationship. International Perspectives on Sexual and Reproductive Health 37(2), 58-66.

Davidson AR, Kalmuss D, Cushman LF, Romero D, Heartwell S and Rulin M (1997) Injectable contraceptive discontinuation and subsequent unintended pregnancy among low-income women. American Journal of Public Health 87 (9), 1532-1534. 
Fallon B-O, Janine L, Speizer IS and White JS (2008) Association between contraceptive discontinuation and pregnancy intentions in Guatemala. Revista Panamericana de Salud Pública 23(6), 410-417.

Fisher AA and De Silva V (1986) Satisfied IUD acceptors as family planning motivators in Sri Lanka. Studies in Family Planning 17(5), 235-242.

Fleiss JL, Levin B and Paik MC (2013) Statistical Methods for Rates and Proportions, 3rd edition. John Wiley and Sons Hoboken, NJ.

Hooper DJ (2010) Attitudes awareness compliance and preferences among hormonal contraception users. Clinical Drug Investigation 30(11), 749-763.

Hubacher D, Masaba R, Manduku CK, Chen M and Veena V (2015) The levonorgestrel intrauterine system: cohort study to assess satisfaction in a postpartum population in Kenya. Contraception 91(4), 295-300.

Jain AK, Obare F, Ramarao S and Askew I (2013) Reducing unmet need by supporting women with met need. International Perspectives on Sexual and Reproductive Health 39(3), 133-141.

KNBS, MOH, NACC, KEMRI and NCPD (2015) (2015) Kenya Demographic and Health Survey 2014. Kenya National Bureau of Statistics (KNBS), Ministry of Health (MOH), National Aids Control Council (NACC), Kenya Medical Research Institute (KEMRI) and National Council for Population and Development (NCPD), Nairobi.

Kopec JA and Esdaile JM (1990) Bias in case-control studies. A review. Journal of Epidemiology and Community Health 44 (3), 179.

Machiyama K, Casterline JB, Mumah JN, Huda FA, Obare F and Odwe G et al. (2017) Reasons for unmet need for family planning with attention to the measurement of fertility preferences: protocol for a multi-site cohort study. Reproductive Health 14(1), 23.

Machiyama K and Cleland J (2013) Insights into Unmet Need in Kenya. Project Report, STEP UP Research Programme Consortium, doi https://doi.org/10.17037/PUBS.01012209.

Machiyama K, Huda FA, Ahmmed F, Odwe G, Obare F and Mumah JN et al. (2018) Women's attitudes and beliefs towards specific contraceptive methods in Bangladesh and Kenya. Reproductive Health 15(1), 75.

Marston C, Renedo A, Nyaaba GN, Machiyama K, Tapsoba P and Cleland J (2017) Improving the measurement of fertility regulation practices: findings from qualitative research in Ghana. International Perspectives on Sexual and Reproductive Health 43(3), 111-119.

Mitchel MJ and Thistle P (2004) Acceptability of levonorgestrel subdermal implants versus tubal ligation for long-term contraception in a rural population of Zimbabwe. Contraception 70(6), 483-486.

Oddens BJ (1999) Women's satisfaction with birth control: a population survey of physical and psychological effects of oral contraceptives intrauterine devices condoms natural family planning and sterilization among 1466 women. Contraception 59(5), 277-286.

Peipert JF, Zhao Q, Allsworth JE, Petrosky E, Madden T, Eisenberg D and Secura G (2011) Continuation and satisfaction of reversible contraception. Obstetrics and Gynecology 117(5), 1105-1113.

Rosenberg MJ, Waugh MS and Burnhill MS (1998) Compliance counseling and satisfaction with oral contraceptives: a prospective evaluation. Family Planning Perspectives 30(2), 89-104.

Rosenfeld JA, Zahorik PM, Saint W and Murphy G (1993) Women's satisfaction with birth control. Journal of Family Practice 36(2), 169-174.

Rutenberg N and Watkins SC (1997) The buzz outside the clinics: conversations and contraception in Nyanza Province Kenya. Studies in Family Planning 28(4), 290-307.

Sedgh G, Ashoford LS and Hussain R (2016) Unmet Need for Contraception in Developing Countries: Examining Women's Reasons for Not Using a Method. The Guttmacher Institute. URL: http://www.guttmacher.org/report/unmet-need-forcontraception-in-developingcountries.

Sedgh G, Singh S and Hussain R (2014) Intended and unintended pregnancies worldwide in 2012 and recent trends. Studies in Family Planning 45(3), 301-314.

Sharan M, Ahmed S, May J and Soucat A (2011) Family Planning Trends in Sub-Saharan Africa: Progress, Prospects and Lessons Learned. Yes Africa Can: Success Stories from a Dynamic Continent. International Bank for Reconstruction and Development/ World Bank, Washington DC, pp. 445-463.

Trlin AD and Perry PE (1982) The oral contraceptive pill: use user satisfaction side effects and fears among Manawatu women. New Zealand Medical Journal 95(717), 700-703.

Van Doorn J (2008) Is there a halo effect in satisfaction formation in business-to-business services? Journal of Service Research 11(2), 124-141.

Yee L and Simon M (2010) The role of the social network in contraceptive decision-making among young African American and Latina women. Journal of Adolescent Health 47(4), 374-380.

Cite this article: Odwe, G. et al. 2018. Factors influencing satisfaction with oral contraceptive pills and injectables among past users in Kenya. Journal of Biosocial Science 51: 491-504, doi:10.1017/S0021932018000299 